\title{
Determination of uranium at ultra trace level in packaged drinking water by laser fluorimeter and consequent ingestion dose
}

\author{
S.K. SAHOO ${ }^{1}$, S. MOHAPATRA ${ }^{1}$, A. CHAKRABARTY ${ }^{1}$, C.G. SUMESH ${ }^{1}$, \\ V.N. JHA ${ }^{1}$, R.M. TRIPATHI ${ }^{1}$, V.D. PURANIK ${ }^{1}$
}

(Manuscript received 24 March 2009, accepted 25 November 2009)

ABSTRACT Precise and accurate estimation of natural radioactivity is essential in order to appraise the radiation dose to the member of public due to various intakes. In the present study, an attempt has been made to estimate the uranium content in packaged drinking water by laser induced fluorimetry and then to calculate the committed effective dose. Sixty packaged drinking water samples of different brands were analysed for uranium content. The total uranium content in these samples was found to be in the range of $0.04-3.88 \mu \mathrm{gl}^{-1}$. The concentration of uranium is comparable with other reported worldwide values except a few high values such as $0.5-6000 \mu \mathrm{g} \mathrm{l}^{-1}$ in Finland, 0.1-28 $\mathrm{g} \mathrm{I}^{-1}$ in China, 0.1-40 $\mu \mathrm{g} \mathrm{I}^{-1}$ in Switzerland and 0.04-1400 $\mu \mathrm{g}^{-1}$ in Jordan and much lower than the drinking water limit of $15 \mu \mathrm{g} \mathrm{I}^{-1}$ (WHO, 2004) and $30 \mu \mathrm{g} \mathrm{l^{-1 }}$ (USEPA, 2000a). The radiation dose due to uranium ingestion through packaged drinking water was found to vary from $0.08-3.19 \mu \mathrm{Sv} \mathrm{y}^{-1}$, with an average dose of $1.21 \mu \mathrm{Sv} \mathrm{y}^{-1}$.

Keywords: Ingestion dose / uranium / packaged drinking water / laser fluorimetry

RÉSUMÉ Détermination d'ultra trace d'uranium dans l'eau potable en bouteille, par fluorimétrie laser et dose par ingestion associée.

L'évaluation précise de la radioactivité naturelle est essentielle afin d'évaluer les doses de rayonnement pour le public suite à diverses incorporations. Dans la présente étude, une tentative a été faite estimer le contenu en uranium de l'eau potable en bouteille par fluorimétrie laser ainsi que le calcul de la dose efficace engagée qui en résulte. Le contenu en uranium a été analysé dans soixante échantillons d'eau potable en bouteille de différentes marques. Le contenu en uranium dans varie de $0,04-3,88 \mu \mathrm{gl}^{-1}$. La concentration en uranium est comparable à d'autres valeurs mesurées dans le monde exception faite de quelques valeurs élevées telles que 0,5-6000 $\mu \mathrm{g} \mathrm{l}^{-1}$ en Finlande, 0,1-28 $\mu \mathrm{g} \mathrm{l}^{-1}$ en Chine, 0,1-40 $\mathrm{\mu g} \mathrm{l}^{-1}$ en Suisse et 0,04-1400 $\mu \mathrm{g} \mathrm{I}^{-1}$ en Jordanie. La concentration mesurée est inférieure à la limite « eau potable » de $15 \mu \mathrm{g} \mathrm{l}^{-1} \mathrm{de} \mathrm{l}^{\prime}$ OMS (2004) et de $30 \mu \mathrm{g} \mathrm{l}^{-1}$ de l'USEPA (2000a). La dose de rayonnement due à l'ingestion d'uranium contenue dans l'eau en bouteille varie de $0,08-3,19 \mu \mathrm{Sv} \mathrm{y}^{-1}$, avec une dose moyenne de $1,21 \mu \mathrm{Sv} \mathrm{y}^{-1}$.

\footnotetext{
1 Environmental Assessment Division, Bhabha Atomic Research Centre, Trombay, Mumbai 400 085, India.
} 


\section{Introduction}

Natural radioactivity and radiation have always been a part of the environment since the inception of the earth (Puranik et al., 2005). It has been observed that the average global natural radiation exposure is around $2.4 \mathrm{mSv} \mathrm{y}^{-1}$ (UNSCEAR, 2000). Broadly natural radiation exposure can be classified into four groups, cosmic, terrestrial, inhalation and ingestion through air, water and food materials (Benville et al., 1987). Except cosmic rays, in all other three groups' uranium plays an important role in delivering radiation dose to members of the public. Being a primordial radionuclide, uranium is omnipresent and poses some radiation risk to human life according to present ICRP recommendation (ICRP, 2007). Therefore, accurate estimation of the concentration of uranium in various environmental matrices such as water, food materials, etc. is very imperative for natural radiation exposure assessment and to estimate the public dose. Packaged drinking water is generally accepted as a safe source of water which contains biological or chemical toxin at levels that are not critical to human health. Many cutting-edge technologies are implemented to process the local ground water to remove all unwanted things and to make the packaged drinking water nearly toxin free (WHO, 2004). In spite of all these processes packaged drinking water may contains very small amount of uranium, occurring naturally in ground water. Therefore, it is essential to determine the total uranium content in packaged drinking water and subsequent committed effective dose to public via ingestion pathway.

\section{Sample collection and processing}

Sixty packaged drinking water samples of various national and regional manufacturers were brought from different states like Andhra Pradesh, Assam, Delhi, Goa, Haryana, Karnataka, Kerala, Madhya Pradesh, Maharashtra, Nagaland, Orissa, Tamilnadu, West Bengal, etc. Two liters of each sample were taken for analysis of uranium content. The $\mathrm{pH}$ of most of the samples was found to be in the range of 6.5-7.5. Samples were transferred to pre-acid cleaned beakers and preconcentrated by evaporation and then ready for analysis by laser fluorimeter.

\section{Instrumentation and analysis}

Laser fluorimeter is an analytical instrument of which the principle is fluorescence of uranyl complex enhanced by addition of sodium pyrophosphate as fluorescence enhancement reagent. In this technique, the sealed-off nitrogen laser is the excitation source which emits a very intense, short lived pulse (7 ns) ultra violet light $(337.1 \pm 0.1 \mathrm{~nm})$, with maximum energy is $20 \mu \mathrm{J}$ at a repetition rate of 
10 pulses per seconde. This excites the uranyl complex in the aqueous medium (Williams et al., 1983, Billard et al., 2003). The excited uranium complex emits green lights (496-565 nm, 4 peaks) that are measured by a photomultiplier tube (PMT) (Veselsky et al., 1988). The organic matter present in natural water also fluoresces when excited by the nitrogen laser, but has very short life time $(<100 \mathrm{~ns})$. The fluorescence of uranyl complex has a longer life time ( $>25 \mu \mathrm{s})$. By measuring the delayed fluorescence signal (a few microsecond after the laser pulse), the unwanted fluorescence of organic compounds are ignored and only the fluorescence of uranyl complex is collected by the time gated PMT. In addition to this, the fluorescence of organic matters has a wavelength maximum around $400 \mathrm{~nm}$ whereas that of uranyl complex is around $500 \mathrm{~nm}$. Therefore, the wavelength filters at $450 \mathrm{~nm}$ significantly curtail the interferences of organic matters. The water samples were analyzed by standard addition method, in order to avoid the matrix effect. Sodium pyro phosphate $\left(\mathrm{Na}_{4} \mathrm{P}_{2} \mathrm{O}_{7} \cdot 10 \mathrm{H}_{2} \mathrm{O}\right)$ was used as fluorescence enhancement reagent, as well as a complexing agent (Sahoo et al., 2008). The details of the optimization of method and analysis protocol are given elsewhere (Rathore et al., 2001; Sahoo et al., 2009).

\section{Quality assurance and quality control}

The quality of the data is assured by cross method analysis. Ten water samples were analysed by both laser fluorimeter and UV fluorimetry, which is one of the accepted and standard recommended method for ultra trace uranium analysis. The results are in good agreement with each other and the correlation coefficient of 0.97 has been observed (Fig. 1). The reliability of the method is assured by spike recovery and replicate analysis.

All laboratory glassware used for sample processing was soaked in $10 \%$ nitric acid for 15 days and then rinsed thoroughly with distilled and double distilled water, respectively before use. Reagent blank was taken along with each batch of sample preparation and concentrations observed in the reagent blank were subtracted from the same batch of samples.

\section{Results and discussion}

Water intake is an essential part of human diet. Water contains ppb or sub-ppb levels of uranium depending on local geology and geochemistry (Frengstand et al., 2000). Once uranium enters to human body, it delivers radiation dose through its alpha emission. It is also a well-known nephrotoxic heavy metal exerting its detrimental effects by chemical action mostly in the proximal tubules in humans (USEPA, 2000a; Paquet et al., 2006). In soil, sediment and sand samples it occurs 


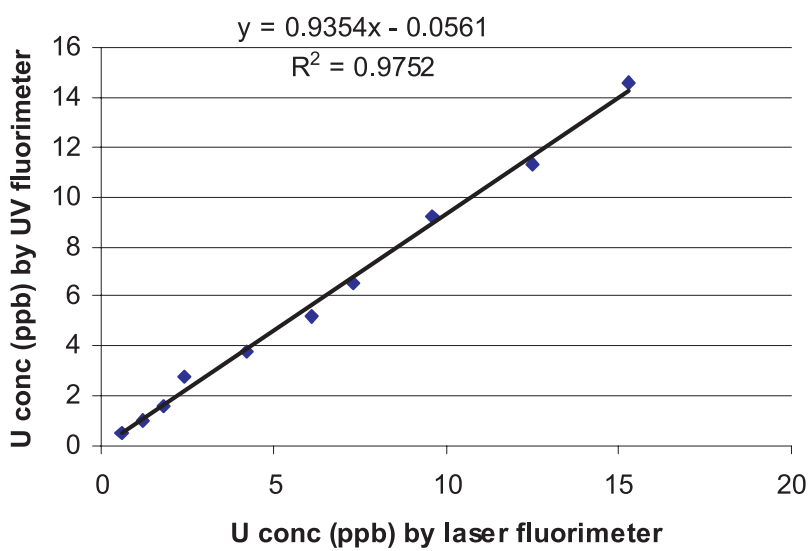

Figure 1-Comparison of uranium concentration by two techniques: laser fluorimetry and UV fluorimetry.

Comparaison des concentrations d'uranium obtenues par deux techniques, la spectrofluorimétrie laser et la fluorimétrie $U V$.

at trace levels whereas in water samples at ultra-trace levels. Therefore, the precise and accurate measurement of uranium in water samples is tedious and time consuming in the presence of other chemical contaminants (Tosheva et al., 2004). For the estimation of uranium in water samples at nanogram level, laser fluorimetry is one of the most sensitive and quick instrumental technique, in which water samples can be directly measured without any radiochemical separation. The minimum detection level of this technique is $0.2 \mu \mathrm{g} \mathrm{l}^{-1}$.

The total uranium content in packaged drinking samples was found to be in the range of $0.04-3.88 \mu \mathrm{g} \mathrm{l}^{-1}$. Nine samples were found to be below the method detection level of $0.2 \mu \mathrm{g} \mathrm{l}^{-1}$ and can be assumed as half of the method detection level for further calculation (USEPA, 2000b). The mean uranium content in packaged drinking water samples was found to be $1.47 \pm 1.1 \mu \mathrm{g} \mathrm{l^{-1 }}$. The first quartile, median and 3rd quartile of the data was found to be $0.44,1.29$ and $2.29 \mu \mathrm{g} \mathrm{l}^{-1}$, respectively and the box-whisker plot of the data is given in Figure 2. The coefficient of skewness was found to be 0.39 . This indicates the data is leftskewed as nine data were below MDL. The frequency distribution and cumulative percentage frequency are given in Figure 3. From the histogram, it is very clear that high frequency was observed in the lower range. The cumulative percentage frequency is not precisely linear but approximately linear. This gives an idea about the nearly normal distribution of uranium content in packaged drinking water. Table I gives the concentration of uranium in drinking water samples in different countries. This shows the compatibility of the obtained concentration with other 
DETERMINATION OF URANIUM AT ULTRA TRACE LEVEL IN PACKAGED DRINKING WATER

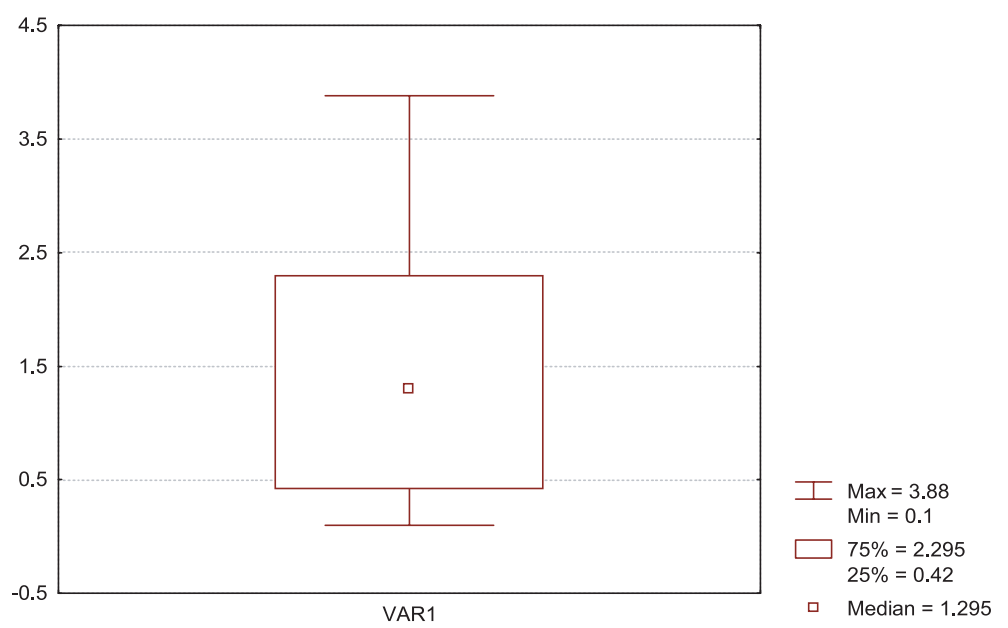

Figure 2-Box whisker plot of the data.

Représentation des données.

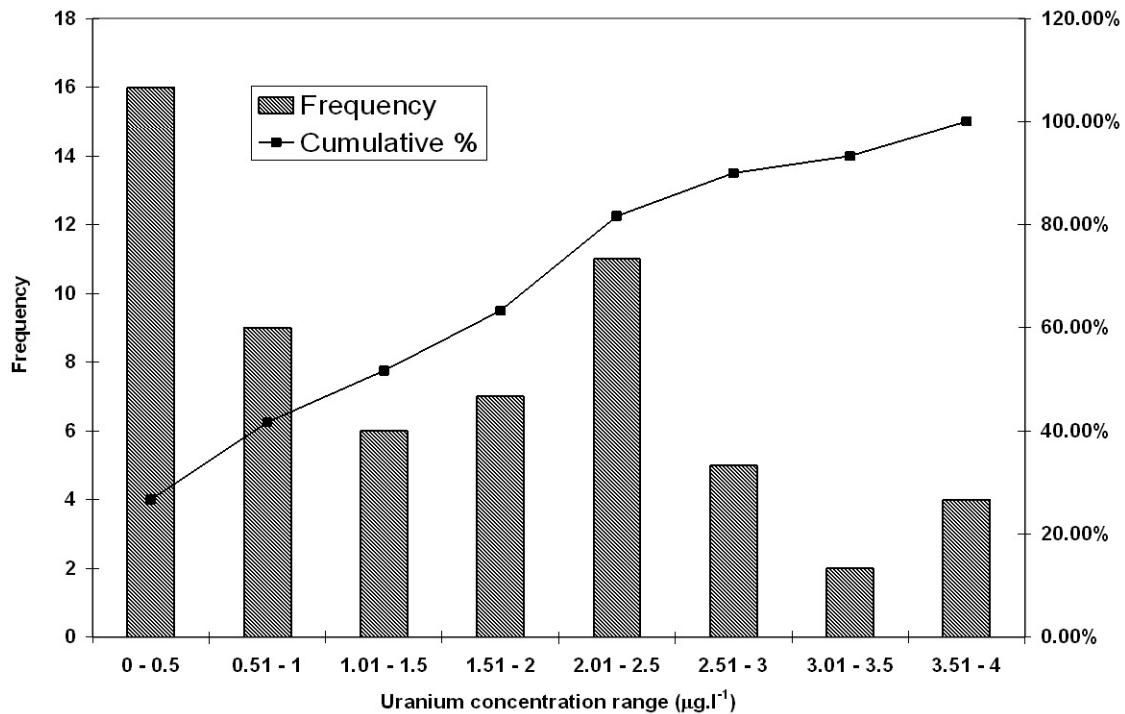

Figure 3 - Histogram and cumulative percentage plot of data.

Histogramme et pourcentage cumulé des données. 
TABLE I

Uranium concentration range in world wide drinking water samples. Concentration en uranium dans différentes eaux potables dans le monde.

\begin{tabular}{|c|c|c|c|c|}
\hline Sr. No. & Country & $\begin{array}{l}\text { Range of uranium } \\
\text { concentration }\left(\mu \mathrm{g} \mathrm{I}^{-1}\right)\end{array}$ & $\begin{array}{l}\text { Average value } \\
\left(\mu \mathrm{g} \mathrm{I}^{-1}\right)\end{array}$ & References \\
\hline 1 & Ontario, Canada & $0.05-4.21$ & 0.40 & OMEE (1996) \\
\hline 2 & USA & - & 2.55 & USEPA $(1991,2000 a, 2000 b)$ \\
\hline 3 & Argentina & $0.04-11.0$ & 1.3 & Bomben et al. (1996) \\
\hline 4 & New Mexico & $>20 \mu \mathrm{g} \mathrm{l}^{-1}$ & - & Hankonson-Hayes et al. (2002) \\
\hline 5 & Central Australia & $>20 \mu \mathrm{g} \mathrm{l}^{-1}$ & - & Hostetler et al. (1998) \\
\hline 6 & Jordan & $0.04-1400$ & 2.4 & Smith et al. (2000) \\
\hline 7 & Finland, Europe & $0.02-6000$ & - & UNSCEAR, 2000 \\
\hline 8 & China, Asia & $0.004-28$ & & UNSCEAR, 2000 \\
\hline 9 & Switzerland, Europe & $0-40$ & - & UNSCEAR, 2000 \\
\hline 10 & Kuwait & $0.02-2.48$ & - & Bou-Rabee (1995) \\
\hline 11 & Turkey & $0.24-17.65$ & - & Kumru (1995) \\
\hline 12 & India & $0.08-471.27$ & - & Singh et al. $(1993,2003)$ \\
\hline 13 & United States & $0.012-3.08$ & - & UNSCEAR, 2000 \\
\hline 14 & France, Europe & $0.18-37.2$ & - & UNSCEAR, 2000 \\
\hline 15 & Spain, Europe & $0.15-0.18$ & - & UNSCEAR, 2000 \\
\hline 16 & Romania, Europe & $0.02-1.48$ & - & UNSCEAR, 2000 \\
\hline 17 & Italy & $0.02-5.2$ & - & UNSCEAR, 2000 \\
\hline 18 & Germany & $0.02-24$ & - & UNSCEAR, 2000 \\
\hline 19 & India & $0.04-3.38$ & 1.47 & Present study \\
\hline
\end{tabular}

reported values worldwide except a few high vales such as $0.5-6000 \mu \mathrm{g}^{-1}$ in Finland, 0.1-28 $\mathrm{g} \mathrm{l}^{-1}$ in China, 0.04-1400 $\mu \mathrm{g} \mathrm{l}^{-1}$ in Jordan and 0.1-40 $\mu \mathrm{g} \mathrm{l}^{-1}$ in Switzerland.

\section{Estimation of radiation dose}

Ingestion dose due to intake of uranium was calculated using the IAEA dose conversion factors for ingestion (BSS, 1996) and the average water intake rate 2 liters per day was assumed. The dose was calculated by using the following basic formula in equation (1) (Bronzovic and Marovic, 2005; Rani et al., 2006)

$$
\text { Dose }\left(\operatorname{Sv~d}^{-1}\right)=\text { Conc. }\left(\mathrm{Bq} \mathrm{1}^{-1}\right) \times \operatorname{Intake}\left(\mathrm{l} \mathrm{d}^{-1}\right) \times \operatorname{DCF}\left(\operatorname{Sv~Bq}{ }^{-1}\right)
$$

where DCF $=$ Dose Conversion Factor, provide by BSS, IAEA used to convert the activity to dose for corresponding intake. 


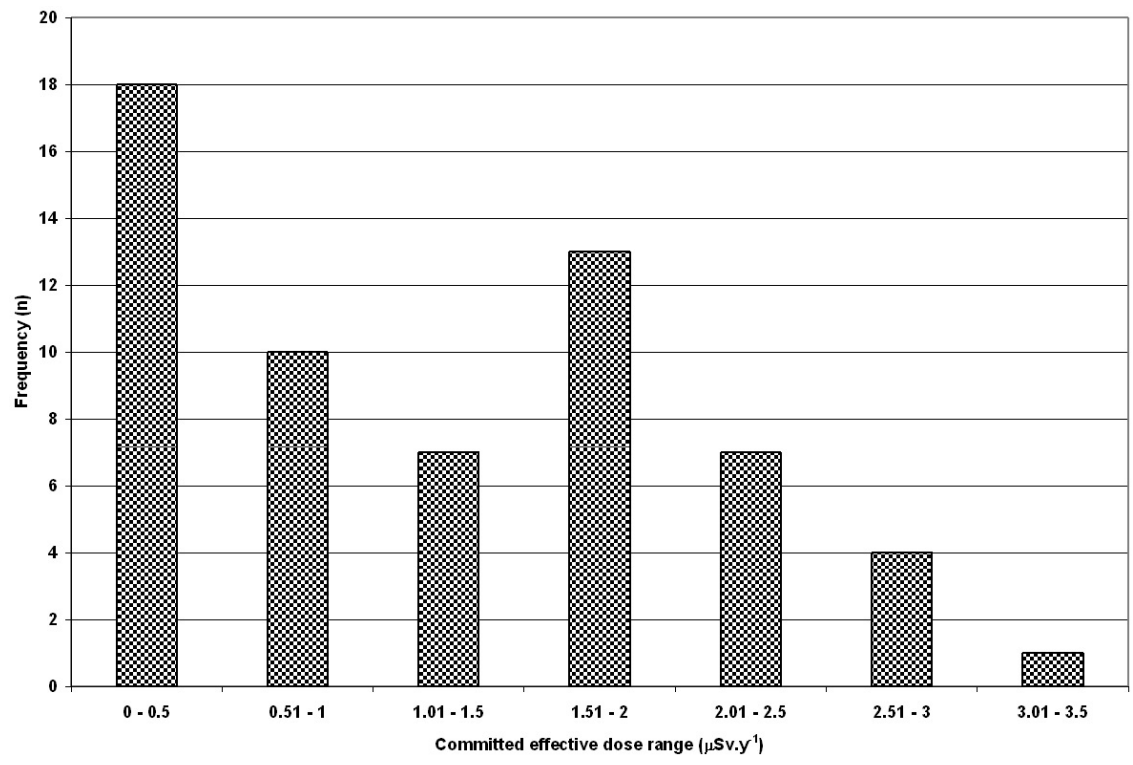

Figure 4 - Frequency distribution of radiation dose due to intake of uranium.

Distribution de la fréquence de doses engagée due à l'incorporation d'uranium.

In the present study, for natural uranium mass to activity conversion factor used is $25 \mathrm{mBq} \mathrm{1}{ }^{-1}$. There after only ${ }^{238} \mathrm{U}$ isotope was considered for dose calculation to simplify the calculation (details are given in Annexe) and the dose conversion factors of ${ }^{238} \mathrm{U},{ }^{235} \mathrm{U}$ and ${ }^{234} \mathrm{U}$ are similar. The coefficient for committed effective dose per unit intake used that of ${ }^{238} \mathrm{U}$ is $4.5 \times 10^{-8} \mathrm{~Sv} \mathrm{~Bq}^{-1}$. The uranium activity concentration of in packaged drinking water samples was found to vary between 2.5-97 $\mathrm{mBq}^{-1}$, with an average value of $36.75 \mathrm{mBq}^{-1}$. The committed effective dose due to uranium through packaged drinking water intake was found to vary from $0.08-3.19 \mu \mathrm{Sv} \mathrm{y}^{-1}$, with an average value of $1.21 \mu \mathrm{Sv} \mathrm{y}^{-1}$. The committed dose estimated in the present study is comparable to other reported value of 1.43-3.79 $\mu \mathrm{Sv} \mathrm{y}{ }^{-1}$ for Himachal Pradesh and $2.18 \mu \mathrm{Sv} \mathrm{y}^{-1}$ for Jaduguda region but lower than 7.56-24.65 $\mu \mathrm{Sv} \mathrm{y}^{-1}$ Punjab in India (Rani et al., 2006; Tripathi et al., 2008). The frequency distribution of committed effective dose due to uranium through packaged drinking water is given in Figure 4.

\section{Conclusion}

Due to the constant increase in consumption of packaged drinking water in recent times, necessity arises to determine the concentration of harmful radionuclides in the packaged drinking water bottles though in minimal level. From the present 
study of the packaged drinking water samples by laser fluorimetry, the total uranium content in these samples varies from 0.04-3.88 $\mu \mathrm{g} \mathrm{I}^{-1}$, which is well within the USEPA drinking water limit of $30 \mu \mathrm{g}^{-1}$ (USEPA, 2000a) and WHO limit of $15 \mathrm{~g} \mathrm{I} \mathrm{l}^{-1}$ (WHO, 2004). The total annual radiation dose due to ingestion of uranium through packaged drinking water is found to be in the range of $0.08-3.19 \mu \mathrm{Sv} \mathrm{y}^{-1}$, with the mean value of $1.21 \mu \mathrm{Sv} \mathrm{y}^{-1}$.

Acknowledgments. Authors are thankful to Shri H.S. Kushwaha, Director, Health, Safety and Environment Group, BARC for his support and encouragement during the work. Thanks are due to Shri S. Raja and Shri Shyam Sunder, Raja Ramanna Centre for Advanced Technology, DAE, India for indigenous development of the laser fluorimeter and constant support. Suggestions and helps from other colleagues during preparation of this manuscript are acknowledged.

\section{Annexe}

Laser induced fluorimeter measures the total uranium present in the aqueous solution.

The specific activity of $\mathrm{U}-238$ is $12.45 \mathrm{~Bq} / \mathrm{mg}$ and that of $\mathrm{U}-235$ is $79.42 \mathrm{~Bq} / \mathrm{mg}$, and $\mathrm{U}-234$ is $2.28 \times 10^{5} \mathrm{~Bq} / \mathrm{mg}$.

The weight abundance of U-238, U-235 and U-234 in natural uranium is $99.27 \%, 0.72 \%$ and $0.005 \%$, respectively.

By considering these weight abundances in natural uranium, the specific activity of U-238 and U-235 in natural uranium will be $12.36 \mathrm{~Bq} / \mathrm{mg}$ and $0.57 \mathrm{~Bq} / \mathrm{mg}$, respectively.

As U-234 occurs in the U-238 radioactive series and they are isotopes of uranium so behave chemically similar. If they are in radioactive secular equilibrium, which is expected in natural environment, the specific activity of $\mathrm{U}-234$ in natural uranium is $12.3 \mathrm{~Bq} / \mathrm{mg}$. There are reported values for the ratio of ${ }^{234} \mathrm{U} /{ }^{238} \mathrm{U}$ in water samples and found to be in the range of 1.07-2.60 (PietrzakFlis et al., 2005) and 0.98-1.43 (Kronfeld et al., 2004). That means the isotopic ratio remains almost undisturbed due to natural processes.

The specific activity of natural uranium due to the three isotopes is estimated to be $25.2 \mathrm{~Bq} / \mathrm{mg}$.

Generally for conversion from natural uranium mass to activity, the factor used is $25 \mathrm{~Bq} / \mathrm{mg}$. 
The average uranium concentration observed in packaged drinking waters is $1.47 \mu \mathrm{g} / \mathrm{l}$, the corresponding activity will be $36.75 \mathrm{mBq} / \mathrm{l}$ (due to all the three isotopes).

\begin{tabular}{ccccccc}
\hline $\begin{array}{c}\text { Isotopes in } \\
\text { natural U }\end{array}$ & $\begin{array}{c}\text { Half-life } \\
(\mathrm{Y})\end{array}$ & $\begin{array}{c}\text { Specific activity } \\
\text { (Individual) } \\
(\mathrm{Bq} / \mathrm{mg})\end{array}$ & $\begin{array}{c}\text { Mass } \\
\text { abundance } \\
(\%)\end{array}$ & $\begin{array}{c}\text { Specific } \\
\text { activity } \\
(\mathrm{Bq} / \mathrm{mg})\end{array}$ & $\begin{array}{c}\text { Activity } \\
\text { abundance } \\
(\%)\end{array}$ & $\begin{array}{c}\text { Committed effective dose } \\
\text { per unit intake by ingestion } \\
\left(\mathrm{Sv} \mathrm{Bq}^{-1}\right) \text { for public } \\
(\mathrm{BSS}, 1996)\end{array}$ \\
\hline 238 & $4.47 \times 10^{9}$ & 12.45 & 99.27 & 12.3 & 49 & $4.5 \times 10^{-8}$ \\
235 & $7.04 \times 10^{8}$ & 80.09 & 0.72 & 0.57 & 2 & $4.7 \times 10^{-8}$ \\
234 & $2.44 \times 10^{5}$ & $232.1 \times 10^{3}$ & 0.005 & 12.3 & 49 & $4.9 \times 10^{-8}$ \\
Total & & & & $\mathbf{2 5 . 2}$ & $\mathbf{1 0 0}$ & \\
\hline
\end{tabular}

\section{Option 1}

The average concentration of uranium i.e. $1.47 \mu \mathrm{g} \mathrm{l}^{-1}$ can be fractioned into three isotopes according to their mass abundances and then can be converted to activity by multiplying the individual specific activity :

- ${ }^{238} \mathrm{U}=1.47 \times 0.9927 \times 12.45=18.17 \mathrm{mBq} / \mathrm{l}$

- ${ }^{235} \mathrm{U}=1.47 \times 0.0072 \times 80.09=0.85 \mathrm{mBq} / \mathrm{l}$

- ${ }^{234} \mathrm{U}=1.47 \times 0.00005 \times 2.28 \times 10^{5}=17.06 \mathrm{mBq} / \mathrm{l}$

- committed dose due to ${ }^{238} \mathrm{U}=18.17 \times 2 \times 365 \times 4.5 \times 10^{-8}=0.59 \mu \mathrm{Sv} / \mathrm{y}$

- committed dose due to ${ }^{235} \mathrm{U}=0.85 \times 2 \times 365 \times 4.7 \times 10^{-8}=0.03 \mu \mathrm{Sv} / \mathrm{y}$

- committed dose due to ${ }^{234} \mathrm{U}=17.06 \times 2 \times 365 \times 4.9 \times 10^{-8}=0.61 \mu \mathrm{Sv} / \mathrm{y}$

- total committed dose due to natural uranium $\quad=1.23 \mu \mathrm{Sv} / \mathrm{y}$

It is quite interesting that the mass abundance of U-234 is very low as compared to U-238 and U-235 but the committed dose delivered by it higher than both of them.

\section{Option 2}

The activity level $36.75 \mathrm{mBq} / \mathrm{l}\left(\right.$ i.e. $1.47 \mu \mathrm{g} \mathrm{l}^{-1} \times 25 \mathrm{mBq} / \mu \mathrm{g}$ ) can be assumed totally due to U-238 and ingestion dose can be calculated.

Committed dose $=36.75 \mathrm{mBq} / 1 \times 2 \mathrm{1} / \mathrm{d} \times 365 \mathrm{~d} / \mathrm{y} \times 4.5 \times 10^{-8} \mathrm{~Sv} / \mathrm{Bq}=$ $1.21 \mu \mathrm{Sv} / \mathrm{y}$. 


\section{Option 3}

The total natural uranium activity can be fractioned according to there activity abundance into individual isotope activities and then corresponding committed dose can be estimated.

\begin{tabular}{ccccc}
\hline $\begin{array}{c}\text { Isotopes in } \\
\text { natural } \mathrm{U}\end{array}$ & $\begin{array}{c}\text { Activity } \\
\text { abundance } \\
(\%)\end{array}$ & $\begin{array}{c}\text { Activity of } \\
\mathrm{U} \text { isotopes } \\
(\mathrm{mBq} / \mathrm{L})\end{array}$ & $\begin{array}{c}\text { Committed effective dose per unit } \\
\text { intake by ingestion }\left(\mathrm{Sv} \mathrm{Bq} \mathrm{Bq}^{-1}\right) \\
\text { public } \\
(\mathrm{BSS}, 1996)\end{array}$ & $\begin{array}{c}\text { Committed dose due to individual } \mathrm{U} \\
\text { isotopes }(\mu \mathrm{Sv} / \mathrm{y}) \\
\text { Intake }=2 \mathrm{l} / \mathrm{d} \\
\text { Time }=365 \mathrm{~d} / \mathrm{y}\end{array}$ \\
\hline $\mathrm{U}-238$ & 49 & 18.007 & $4.5 \times 10^{-8}$ & 0.59 \\
$\mathrm{U}-235$ & 2 & 0.735 & $4.7 \times 10^{-8}$ & 0.025 \\
\hline U-234 & 49 & 18.007 & $4.9 \times 10^{-8}$ & 0.64 \\
\hline Total & 100 & & & 1.25 \\
\hline
\end{tabular}

In all the three options the committed effective dose is almost comparable. Therefore, generally many researchers follow the second option assuming the origin is natural and the isotopic ratio is undisturbed which is easier to compute and convincing also. In addition, the dose conversion factors of three isotopes are comparable.

For conversion of uranium mass (obtained by chemical method or instrument) to activity assuming ${ }^{238} \mathrm{U}(12.3 \mathrm{~Bq} / \mathrm{mg})$ only and then dose calculation gives half of the dose delivered to public. Thus, we have used the mass-to-activity factor of $25 \mathrm{~Bq} / \mathrm{mg}$ and dose conversion factor of ${ }^{238} \mathrm{U}$ for dose calculation (Rani et al., 2006).

\section{REFERENCES}

Benville A. et al. (1987) Human Population Exposures to Cosmic Radiation, In: 4th International Conference on the Natural Radiation Environment, Lisbon, Portugal.

Billard I. et al. (2003) Equilibrium constants in aqueous lanthanide and actinide chemistry from timeresolved fluorescence spectroscopy: The role of ground and excited state reactions, Radiochim. Acta 91, 285-294.

Bomben A.M. et al. (1996) Ra-226 and natural uranium in Argentina bottled mineral waters, Radiat. Prot. Dosim. 6, 221-224.

Bou-Rabee F. (1995) Estimating the concentration of uranium in some environmental samples in Kuwait after the 1991 Gulf War, Appl. Radiat. Isotopes 46, 217-220.

Bronzovic M., Marovic G. (2005) Age-dependent dose assessment of Ra-226 from bottled water intake, Health Phys. 88, 480-485.

BSS (1996) International Basic Safety Standards for Protection against Ionizing Radiation and for Safety of Radiation Sources, Safety Series no 115.

Frengstad B. et al. (2000) The chemistry of Norwegian groundwater's, III. The distribution of trace elements in 476 crystalline bedrock groundwater's, as analysed by ICP-MS techniques, Sci. Tot. Environ. 31, 21-40. 
Hakonson-Hayes A.C. et al. (2002) Assessing potential risks exposure to natural uranium in well water, J. Environm. Radioact. 59, 29-40.

Hostetler S. et al. (1998) Groundwater quality in the Papunya-Kintore region, Northern Territory, Canberra, Australian Geological Survey Organisation.

ICRP Publication 103 (2007) The Recommendations of International Commission on Radiological Protection, Ann. ICRP 37(2-4).

Kronfeld J., Godfrey-Smith D.I., Johannessen D., Zentilli M. (2004) Uranium series isotopes in the Avon Valley, Nova Scotia, J. Environm. Radioact. 73, 335-352.

Kumru M.N. (1995) Distribution of radionuclides in sediments and soils along the Büyük Menderes River, Proc. Pakistan. Acad. Sci. 32, 51-56.

OMEE (1996) Ontario Ministry of Environment and Energy, Monitoring data for uranium1990-1995, Toronto, Ontario, OMEE. Ontario Drinking Water Surveillance Program.

Paquet F. et al. (2006) Accumulation and distribution of uranium in rats after chronic exposure by ingestion, Health Phys. 90, 139-147.

Pietrzak-Flis Z., Kaminska I., Chrzanowski E. (2005) Uranium isotopes in public drinking water and dose assessment for man in Poland, Rad. Prot. Dosim. 113 (1), 34-39.

Puranik V.D. et al. (2005) Natural and man-made environmental background radiation exposure levels, a review, In 14th National Symposium on Environment, Hyderabad.

Rani A. et al. (2006) Analysis of uranium in drinking water samples using laser induced fluorimetry, Health Phys. 91, 101-107.

Rathore D.P.S. et al. (2001) Application of a differential technique in laser-induced fluorimeter, simple and a precise method for the direct determination of uranium in mineralized rocks at the percentage level, Analyt. Chim. Acta 434, 201-208.

Sahoo S.K. et al. (2008) Optimization of Method Parameters for Estimation of Uranium at Nanogram Level in Drinking Water Samples by Laser Fluorimeter, In Proc. of Indian Analytical Science Congress, pp.111-112.

Sahoo S.K. et al. (2009) Concentration of Uranium in Packaged Drinking Water by Laser Fluorimetry, In: 8th DAE-BRNS National Laser Symposium, Cat. 11-2-1-2.

Singh P. et al. (1993) Quantitative determination of uranium in water samples from Jhansi and Allahabad, In: 7th Nat. Symposium of Srivastava DS, Prasad R. (Ed.). Achal Tal, Aligarh, India, Litho Offset Printers, SSNTD 197-201.

Singh P. et al. (2003) Analysis of uranium and its correlation with some physico-chemical properties of drinking water samples from Amritsar, Punjab, J. Environ. Mon. 5, 917-921.

Smith B. et al. (2000) Identification, investigation and remediation of ground water containing elevated levels of uranium-series radionuclides, a case study from the Eastern Mediterranean, In: 3rd International Conference on the Geology of the Eastern Mediterranean, Panayides L., Xenophotons C., Malpas J. (Eds.). Nicosia, Cyprus, Geneva, World Health Organization, WHO/SDE/PHE/01.1.

Tosheva Z. et al. (2004) Comparison of different methods for uranium determination in water. $J$. Environm. Radioact. 72, 47-55.

Tripathi R.M., Sahoo S.K., Jha V.N., Khan A.H., Puranik V.D. (2008) Assessment of environmental radioactivity at uranium mining, processing and tailings management facility at Jaduguda, India, Journal of Applied Radiation and Isotopes 66, 1666-1670.

UNSCEAR (2000) United Nations Scientific Committee on the Effect of Atomic radiation, United Nations General Assembly, United Nations, Vol. 1, Annex B, pp 84-140, New York.

USEPA (1991) U.S. Environmental Protection Agency, Review of RSC analysis, Report prepared by Wade Miller Associates (follow-up to USEPA 1990), New York. 
USEPA (2000a) United States Environmental Protection Agency, National Primary Drinking Water Regulations, Radionuclides Final Rule, 40 CFR Parts 9, 141, and 142, pp. 76708-76712.

USEPA (2000b) Guidance for Data Quality Assessment, EPA QA/G-9, Section 4.7.

Veselsky J.C., Kwiecinska B., Wehrstein E., Suschny O. (1988) Determination of uranium in minerals by laser fluorimeter, Analyst. 113, 451-455.

Williams et al. (1983). The determination of uranium in aqueous samples by means of a pulsed-source fluorescence spectrometer. Analytica Chimica Acta, 154, 341-345.

WHO (2004) Guidelines for drinking water, Vol.1 Recommendations, pp. 145-196. 